\title{
Chemical Composition of Urtica simensis Grown in Different Regions of Ethiopia
}

\author{
Koju Bedekach Bayba, ${ }^{1}$ Amare Aregahegn Dubale, ${ }^{1}$ Bewketu Mehari, ${ }^{2}$ \\ and Minaleshewa Atlabachew $\mathbb{1}^{3}$ \\ ${ }^{1}$ Department of Chemistry, College of Natural and Computational Science, Energy and Environment Research Center, \\ Dilla University, Dill 419, Ethiopia \\ ${ }^{2}$ Department of Chemistry, Faculty of Natural and Computational Sciences, University of Gondar, Gondar, Ethiopia \\ ${ }^{3}$ Department of Chemistry, College of Science, Bahir Dar University, P.O. Box 79, Bahir Dar, Ethiopia
}

Correspondence should be addressed to Minaleshewa Atlabachew; atminale2004@yahoo.com

Received 10 August 2019; Revised 14 February 2020; Accepted 2 March 2020; Published 30 March 2020

Academic Editor: Marcone A. L. de Oliveira

Copyright (c) 2020 Koju Bedekach Bayba et al. This is an open access article distributed under the Creative Commons Attribution License, which permits unrestricted use, distribution, and reproduction in any medium, provided the original work is properly cited.

Leaf samples of Urtica simensis collected from different locations of Ethiopia were analyzed for their proximate compositions, total phenolic and flavonoid contents, antioxidant activities, and fatty acid profiles. The proximate analysis results revealed the presence of ash in the range $17.2-24.3 \%$, crude fat $3.19-3.50 \%$, crude protein $3.42-6.38 \%$, crude fiber $9.37-14.0 \%$, and carbohydrate 56.7-63.7\%. The determined total polyphenols, flavonoids, and antioxidant activities ranged 2.18-4.84 mg gallic acid, $1.35-4.46 \mathrm{mg}$ catechin, and $1.58-3.36 \mathrm{mg}$ ascorbic acid, respectively, equivalents per gram of dry sample. High variability was observed for polyphenol and flavonoid contents while only random variation was observed for crude fat and carbohydrate among samples from different locations. In addition, the fatty acid profiles of the leaves were analyzed by using gas chromatography coupled with mass spectrometry. A total of 16 different fatty acids were detected in the samples. Linolenic, palmitic, and linoleic acids were the major fatty acids with average compositions of 36.6, 20.7, and 15.5\%, respectively, of the total fatty acid. The result of this study revealed that the carbohydrate and ash contents of leaves of Urtica simensis are exceptionally high to make the leaves a significant source of the dietary important chemicals. Additionally, the lipid fraction of the leaves was found to be rich in essential fatty acids ( $\alpha$-linolenic and linoleic acids) that are critically required in the human diet.

\section{Introduction}

Various wild-grown plants have been used as food and medicine by different ethnic groups across the world. Different parts of the plants, i.e., fruits, seeds, roots, and leaves, have also been utilized by the different cultural groups depending on their customs and indigenous knowledge of preparation. Many of the wild edible plants have also been found to be rich sources of one or more of the nutritionally important substances, such as proteins, carbohydrates, lipids, vitamins, and minerals. Besides the dietary substances, some of them also contain considerable amounts of a variety of health-promoting compounds, such as phenolic compounds [1-4].

Among the wild edible plants is Urtica simensis. The plant belongs to the genus Urtica and family Urticaceae [5].
Urtica simensis is one of the species of the genus Urtica, which comprises about 30 species, which is endemic in Ethiopia. It is a dark green perennial plant whose leaves are used as food by various ethnic groups in Ethiopia [6]. The leaves of the plant are also used for the treatment of various diseases. For example, the leaves are used for the treatment of gastritis in two different forms of preparations [7]. In the first, the leaves are roasted and crushed and the resulting juice is taken orally. In the second, the leaves are cooked with water and eaten with traditional flatbread made out of teff flour (flour made from seeds of Eragrostis tef). The leaves and roots are powdered and mixed with water, and the filtrate is drunk for the treatment of gonorrhea [8]. For the treatment of body swelling, the plant leaves are heated and placed on the affected area topically [8]. The leaves of the plant are crushed and the resulting juice is creamed with 
butter and pasted on the affected body part in the treatment of wound infection [7].

Previous research works have estimated the wild vegetable species most commonly used as food sources by various ethnic groups in Ethiopia [9]. These researches have reported Urtica simensis as one of the wild edible plants for most common utilization in the country. Based on these, the species studied in the present work has been selected.

The leaves of Urtica simensis have been used as seasonal and survival food, especially during periods of drought or food scarcity. The repeated recurrence of drought and war, poor agricultural systems, and rapid population growth have crippled the country into a food-insecure state. In addition, the limited effort made by the country in diversifying its dietary sources has also contributed to the existing food insecurity problem. Considering the availability of Urtica simensis in the wild growing with little effort, the plant has the potential to play an important role in combating food insecurity in the country. For this, an investigation on the nutritional quality of the plant will be crucial to assist the country's efforts towards food security. Despite this, the dietary analysis made on Urtica simensis indigenous in Ethiopia is scarce.

One of the aims of this study was, therefore, to determine the nutritional quality of the leaves of Urtica simensis with respect to its protein, carbohydrate, fat, and fiber contents. The second was to determine the fatty acid profile of the leaves. The third was to determine the level of health-promoting plant secondary metabolites, such as polyphenols and flavonoids, as well as the antioxidant activities of the leaves.

\section{Materials and Methods}

2.1. Chemicals. Toluene and n-hexane (from Supreme Enterprises, Cantt, India), sulfuric acid, hydrochloric acid, boric acid, phosphoric acid, sodium hydroxide, potassium hydroxide, sodium sulfate, potassium sulfate, copper sulfate, sodium chloride, sodium carbonate, sodium nitrite, sodium tungstate, sodium molybdate, aluminum chloride, and ascorbic acid (from BDH, England), catechin, gallic acid, 2,2-diphenyl -1-picrylhydrazyl, undecanoic acid, methyl red, and bromocresol (from Sigma Aldrich) were used in the study.

2.2. Analytical Instruments. The analytical instruments used are as follows: GC-MS (Agilent Technologies 7890B-5977A, China), UV-Vis spectrometer (SP-UV500 DB, Spectrum Instrument, GmbH, Germany), Kjeldahl digestion setup (DK 20, VELP Scientifica), and Kjeldahl distillation and titration (UDK 149 Automatic Kjeldahl Distillation Unit, VELP Scientifica).

2.3. Plant Samples. Samples were collected from six districts belonging to Oromia region and Southern Nations, Nationalities, and Peoples Regional States (SNNPRS) of Ethiopia. The districts Dima, Dodola, and Adaba belong to Oromia region while Hula, Dilla Zuria, and Bule districts belong to SNNPRS. The mean annual rainfall and altitude of the six sampling districts are as follows: Dima $(1244 \mathrm{~mm}$, $2418 \mathrm{~m})$, Dodola $(968 \mathrm{~mm}, 2472 \mathrm{~m})$, Adaba $(908 \mathrm{~mm}$, $2414 \mathrm{~m})$, Hula $(1035 \mathrm{~mm}, 1737 \mathrm{~m})$, Dila Zuria $(1500 \mathrm{~mm}$, $1670 \mathrm{~m})$, and Bule $(1508 \mathrm{~mm}, 2843 \mathrm{~m})$. We used monthly annual mean rainfall estimate of Tropical Rainfall Measuring Mission (TRMM 3B42v7) [10] operational data products for the period 1998 to 2018. For each district, three sampling areas, where the plant is densely populated, were considered and a composite sample was obtained by mixing the three samples of a particular district. During collection, mature plant trees were randomly selected, and from each tree, leaves from the upper shoot were separated from the stem using sanitized protected active gloves starting from the bottom to the tips by stalk position and transferred into plastic bags. In the laboratory, the leaves were cleaned using distilled water and allowed to dry left open in the air in the room. The dried leaves were then milled and sieved to produce flour.

2.4. Proximate Composition Analysis. Dietary analysis, with respect to ash, crude protein, crude fat, crude fiber, and carbohydrate contents, was carried out with the powdered leaves of Urtica simensis following the standard official methods of the analysis of the AOAC (1990) [11]. Briefly, the moisture content was determined by measuring the weight loss of a $5 \mathrm{~g}$ portion of air-dried material after being dried in the oven at $100^{\circ} \mathrm{C}$. The total ash content was determined by heating $5 \mathrm{~g}$ of the sample at $600^{\circ} \mathrm{C}$ in the muffle furnace. The total fat content was determined using $10 \mathrm{~g}$ of an air-dried sample using Soxhlet extractor and n-hexane as an extracting solvent. The crude protein content of the samples was determined using the Kjeldahl digestion and distillation method. A conversion factor of 6.25 was used to obtain the protein content from the determined total nitrogen content. For crude fiber determination, the sample was defatted using petroleum ether and the residue was successively boiled with $0.313 \mathrm{M} \mathrm{H}_{2} \mathrm{SO}_{4}$ and $0.313 \mathrm{M} \mathrm{KOH}$. The insoluble matter was thoroughly rinsed with boiled water and acetone. The residue was dried, weighed, and incinerated at $550^{\circ} \mathrm{C}$ in the furnace. The weight loss on ashing was taken as the crude fiber content. The total carbohydrate content was calculated "by difference" [12].

The determined moisture contents of samples (Table 1) were only used to express chemical compositional data on a dry weight basis. The moisture contents are obviously low, as they were determined in the leaf samples that were air-dried under room temperature conditions left open in the laboratory.

\subsection{Analysis of Fatty Acids}

2.5.1. Extraction of Lipids. Soxhlet apparatus was used for the extraction of lipids. Twenty grams of powdered Urtica simensis leaf sample was extracted with $200 \mathrm{~mL}$ of $\mathrm{n}$-hexane for $6 \mathrm{~h}$, whereafter, the solvent was removed by a rotary evaporator and the residue was reconstituted in $5 \mathrm{~mL}$ of toluene. 
TABle 1: The moisture contents (\% w/w) of the air-dried leaf samples of Urtica simensis.

\begin{tabular}{lcccccc}
\hline Sample & Dilla Zuria & Bule & Hula & Adaba & Dodola & Dima \\
\hline Moisture & $6.4 \pm 0.9$ & $7.4 \pm 1.4$ & $9.7 \pm 1.0$ & $9.0 \pm 1.1$ & $9.4 \pm 1.1$ & $6.8 \pm 1.1$ \\
\hline
\end{tabular}

2.5.2. Derivatization of Fatty Acids. Fatty acids were converted to the corresponding methyl esters prior to GC-MS analysis according to the method reported by Mehari et al. [13]. Briefly, a $1 \mathrm{~mL}$ portion of the lipid extract in toluene was mixed with $2 \mathrm{~mL}$ of $1 \%$ methanolic sulfuric acid solution. To this, $350 \mu \mathrm{L}$ of a solution containing $5.94 \mathrm{~g} \mathrm{~L}^{-1}$ undecanoic acid in n-hexane was added as an internal standard. The mixture was then allowed to react for $12 \mathrm{~h}$ while maintained at $50^{\circ} \mathrm{C}$ in an incubator, whereafter, the mixture was treated with $5 \mathrm{~mL}$ of $5 \%$ aqueous $\mathrm{NaCl}$ solution and extracted twice with each of $6 \mathrm{~mL}$ hexane. The combined hexane extract was dried over anhydrous sodium sulfate and a portion of the extract was filtered by syringe membrane filter directly to a chromatographic vial for GC-MS analysis.

2.5.3. GC-MS Analysis of Fatty Acids. Agilent 7890B gas chromatograph equipped with a 5977A MSD was used. This was coupled with a mass spectrometer operated in electron ionization mode. A fused-silica capillarity column $(30 \mathrm{~m}$, $0.25 \mathrm{~mm}$ ID, $0.25 \mathrm{~mm}$ film thickness) with chemically bonded phases DB-5 MS (J\&W Scientific) was used for the GC separation. The initial oven temperature was $125^{\circ} \mathrm{C}$ that was held for $2 \mathrm{~min}$, then raised at the rate of $30^{\circ} \mathrm{C} / \mathrm{min}$ to $170^{\circ} \mathrm{C}$, then raised at the rate of $15 \mathrm{oC} / \mathrm{min}$ to $200^{\circ} \mathrm{C}$ held for $2 \mathrm{~min}$, and then raised at the rate of $3^{\circ} \mathrm{C} / \mathrm{min}$ to $230^{\circ} \mathrm{C}$ that was held for $20 \mathrm{~min}$. Carrier gas was $\mathrm{He}$ (99.999\%), with a flow rate of $1 \mathrm{~mL} / \mathrm{min}$; injector temperature was $250^{\circ} \mathrm{C}$; the split ratio was $25: 1$. Mass spectra were recorded at $70 \mathrm{eV}$, the mass range was from $\mathrm{m} / \mathrm{z} 40$ to $500 \mathrm{amu}$, the ion source temperature was $230^{\circ} \mathrm{C}$, the quadruple temperature was $150^{\circ} \mathrm{C}$, and the solvent delay time was $3.5 \mathrm{~min}$. The constituents were identified by comparing their mass spectra with those of NIST library data for the GC-MS system.

\subsection{Analysis of Phenolic Compounds}

2.6.1. Extraction of Phenolic Compounds. For the analysis of total phenolic and flavonoid contents and antioxidant activity, extraction was carried out following a method reported by Liu et al. [14] with slight modification. Briefly, one gram of powdered leaves of Urtica simensis was extracted with $25 \mathrm{~mL}$ of $80 \%$ aqueous methanol in an ultrasonic water bath for $1 \mathrm{~h}$. The mixture was then centrifuged at $1000 \mathrm{rpm}$ for $10 \mathrm{~min}$. The supernatant was taken and filtered using filter paper and the filtrate was used for analysis.

2.6.2. Determination of Total Polyphenols. The total phenolic content of the plant leaf samples was determined by using the Folin-Denis reagent according to a procedure described by [15] with some modification. Briefly, a $0.3 \mathrm{~mL}$ sample extract was mixed with $0.75 \mathrm{~mL}$ of Folin-Denis reagent and $1.2 \mathrm{~mL}$ distilled water. After $5 \mathrm{~min}, 3.75 \mathrm{~mL}$ of $10 \% \mathrm{Na}_{2} \mathrm{CO}_{3}$ solution was added to the solution and kept for $30 \mathrm{~min}$ at room temperature in the dark. Subsequently, the absorbance of the solution was measured at $760 \mathrm{~nm}$.

The Folin-Denis reagent was prepared in the laboratory. For this, $10 \mathrm{~g}$ of sodium tungstate $\left(\mathrm{Na}_{2} \mathrm{WO}_{4} \cdot 2 \mathrm{H}_{2} \mathrm{O}\right)$ and $2 \mathrm{~g}$ of sodium molybdate $\left(\mathrm{Na}_{2} \mathrm{MO}_{4} \cdot 2 \mathrm{H}_{2} \mathrm{O}\right)$ were dissolved in a mixture of $75 \mathrm{~mL}$ of distilled water and $5 \mathrm{~mL}$ of $85 \%$ orthophosphoric acid in a $100 \mathrm{~mL}$ round bottom flask. The mixture was then refluxed for $2 \mathrm{~h}$ at $100^{\circ} \mathrm{C}$.

Gallic acid was used as standard and the determined total polyphenol contents were expressed as milligram gallic acid equivalents per gram $\left(\mathrm{mgGAE} \mathrm{g}^{-1}\right)$ of dry sample. For this, a six-point calibration curve was constructed in the range $1-10 \mathrm{mg} \mathrm{L}^{-1}$ of gallic acid with a coefficient of determination 0.999 .

2.6.3. Determination of Total Flavonoids. The total flavonoid content of the plant leaf samples was determined using the aluminum chloride method [15]. Briefly, a $0.3 \mathrm{~mL}$ of sample extract was mixed with $3.4 \mathrm{~mL}$ of water and $0.3 \mathrm{~mL}$ of $5 \%$ aqueous solution of $\mathrm{NaNO}_{2}$ and allowed to react for $5 \mathrm{~min}$, whereafter, $0.3 \mathrm{~mL}$ of $10 \% \mathrm{AlCl}_{3}$ was added to the mixture and allowed to react for another $5 \mathrm{~min}$. Finally, $2 \mathrm{~mL}$ of $1 \mathrm{M}$ $\mathrm{NaOH}$ was added and the absorbance of the resulting solution was measured at $510 \mathrm{~nm}$ against a reagent blank.

Catechin was used as a standard and the determined total flavonoid contents were expressed as milligram catechin equivalent per gram $\left(\mathrm{mgCE} \mathrm{g}^{-1}\right)$ of dry sample. For this, a seven-point calibration curve was constructed in the range $1-15 \mathrm{mg} \mathrm{L}^{-1}$ of catechin with a coefficient of determination 0.999 .

2.6.4. Determination of Antioxidant Activity. The antioxidant activity of the leaf samples was determined based on the $\mathrm{DPPH}$ radical scavenging assay following the method reported by Alamgir et al. [16] with little modification. Briefly, different concentrations, 40,80,160,320,400,600,800, 1600 , and $2400 \mathrm{mg} \mathrm{L}^{-1}$, of sample solution were prepared by diluting the original leaf extract with $80 \%$ aqueous methanol. Two milliliters of the sample solution or standard, for each concentration level, was mixed with $2 \mathrm{~mL}$ of $31.2 \mathrm{mg} \mathrm{L}^{-1}$ $\mathrm{DPPH}$ solution in methanol and incubated for $5 \mathrm{~min}$, whereafter, the volume of the solution was adjusted to $5 \mathrm{~mL}$ with $80 \%$ aqueous methanol and incubated at room temperature for $30 \mathrm{~min}$. The absorbance of the resulting solutions was measured at $517 \mathrm{~nm}$ against a reagent blank. The radical scavenging activity was calculated as follows:

$$
\% \text { scavenging activity }=\frac{A-B}{A} \times 100,
$$

where $A$ is the absorbance of the pure DPPH solution and $B$ is the absorbance of DPPH solution in the presence of the sample. 
Ascorbic acid was used as standard and the determined antioxidant activities were expressed as milligram ascorbic acid equivalents per gram (mgAAE $\mathrm{g}^{-1}$ ) of dry sample. For this, the DPPH radical scavenging activity of ascorbic acid solutions with concentrations $0.1,0.2,0.4,0.8,1.0,1.5,2.0$, 8.0 , and $12 \mathrm{mg} \mathrm{L}^{-1}$ was measured following the same procedure as that of the samples.

2.7. Statistical Analysis. All analyses were done in triplicate. One-way analysis of variance (ANOVA) was used to test the effect of the growing region on the mean concentrations of the different chemical constituents determined. Data analysis was carried out using the statistical software package SPSS 20 (IBM Corporation, USA). Differences were considered significant when $\alpha<0.05$.

\section{Results and Discussion}

3.1. Proximate Composition. The determined proximate composition, which includes ash, fat, protein, fiber, and carbohydrate, of Urtica simensis leaves is shown in Table 2. Data is expressed in percentage by dry weight basis. Carbohydrate content was the highest (56.7-63.7\%), followed by ash (17.2-24.3\%) and crude fiber (9.37-14.0\%). Crude protein and fat contents were in the range of $3.42-6.38 \%$ and $3.19-3.50 \%$, respectively, across the different locations.

Regarding variations in the levels of the determined chemical constituents among the sample locations, the highest variability was observed for crude protein with relative standard deviation (RSD) of $23.2 \%$. Leaf samples from Dima contained a significantly higher amount of crude protein than samples from all the other locations. The least varied constituent was crude fat with RSD of 3.5\%. This was only a random variation as there was no statistically significant difference in the level of crude fat among samples collected from the different locations. Regarding carbohydrate content, only little variation was observed across sampling locations, with RSD of $3.7 \%$. The only observed significant difference was between Dima and Dilla Zuria samples, where leaf samples from Dima contained higher carbohydrate than that from Dilla Zuria. Ash and crude fiber contents show exactly opposite trends among samples. Leaf samples collected from Dilla Zuria and Bule contained significantly higher amounts of ash than samples from Dodola, Adaba, and Hula. Conversely, leaf samples from Dodola, Adaba, and Hula contained significantly higher amounts of crude fiber than samples from Dilla Zuria, Bule, and Dima.

The average dietary contents determined in the six district samples were compared with the values reported for various leafy vegetables in the literature [17-19]. The ash content of the leaves of Urtica simensis (average 19.9\%) is found to be higher than that of most of the common vegetables reported by Shemishere et al. [17], Akinwunmi and Omotayo [18], and Iheanacho et al. [19], except Basella alba (27.4\%) [18], Amaranthus cruentus (25.6\%) [17], Amaranthus dubius (24.5\%), and Amaranthus hybridus (20.3\%) [18]. This implies that the leaves of Urtica simensis are a rich source of minerals. Similarly, the determined carbohydrate content (average 60.3\%) of Urtica simensis leaves is significantly higher than that reported for all of the different vegetables listed [17-19], except for Ocimum gratissimum (62.7\%). This makes the leaves of Urtica simensis nutritionally valuable. It has to be noted that data reported by Shemishere et al. [17] has been recalculated to the dry weight basis using the moisture content values provided in the papers.

Another significant observation is the very low protein content of Urtica simensis leaves (average 4.81\%). This makes the leaves poor source of protein when compared to the other vegetable leaves [17-19].

The crude fat content of Urtica simensis leaves (average $3.34 \%$ ) is found to be lower than that of most of the common vegetables [17-19]. However the determined fat content is higher than the two species of Amaranthus (1.34-1.83\%) and Corchorus olitorius (2.83\%) with similar content to Basella alba and Solanum macrocarpon, for each of which $3.34 \%$ has been reported. Similarly, the average crude fiber content $(11.7 \%)$ of the leaves of Urtica simensis falls in the range moderate to low when compared to the other vegetables.

3.2. Fatty Acid Composition. A total of 16 different fatty acids were detected among samples collected from the six different locations (Table 3 ). All of the 16 fatty acids were detected in samples from Bule and Hula districts (Figure 1), whereas one or more of the fatty acids were not detected in the other samples. Among the detected fatty acids, seven were unsaturated fatty acids, of which 3 were monounsaturated and four were polyunsaturated fatty acids.

$\alpha$-Linolenic, palmitic, and linoleic acids were the most abundant fatty acids found in the leaf samples of Urtica simensis (Table 3). These three fatty acids have also been found to be the major fatty acids in various green vegetables, such as red cabbage, lettuce, and kale [20]. Besides, the leaves contained a considerable amount of arachidic acid. The minor constituents were behenic, lignoceric, stearic, palmitoleic, oleic, and heneicosylic acids. All the remaining six fatty acids were found in trace levels with relative compositions lower than $0.5 \%$. Regarding the effect of growing location, high variability was observed for the trace and minor fatty acids.

The concentrations of those fatty acids with a relative percentage composition higher than $0.5 \%$, hence being quantifiable accurately [21], were determined by comparing the chromatographic peak areas of the analytes with that of a known amount of the internal standard as follows [22]:

$$
\% w / w=\frac{A_{\mathrm{FA}} \times m_{\mathrm{IS}}}{A_{\mathrm{IS}} \times m_{c}} \times 100,
$$

where $A_{\mathrm{FA}}$ is the peak area of the fatty acid, $A_{\mathrm{IS}}$ is the peak area of the internal standard, $m_{\text {IS }}$ is the mass of the internal standard, and $m_{C}$ is the mass of Urtica simensis used for the analysis.

The most abundant fatty acids $\alpha$-linolenic, palmitic, and linoleic acids constituted 41.9, 18.3, and 17.9\%, respectively, of the total quantifiable fatty acids (Table 4 ). These three fatty acids together constituted more than $78 \%$ of the total fatty 
TABle 2: Proximate composition (\% w/w dry matter) of the leaves of Urtica simensis samples collected from six different locations in Ethiopia. The overall mean and standard deviation (SD) across the different samples are also included in the table.

\begin{tabular}{lccccc}
\hline Sample & Ash & Crude fat & Crud protein & Dietary fiber & Total carbohydrate \\
\hline Dilla Zuria & 24.3 & 3.19 & 4.86 & 10.9 & 56.7 \\
Bule & 23.3 & 3.44 & 3.65 & 9.79 & 59.9 \\
Hula & 18.9 & 3.50 & 3.42 & 14.0 & 60.1 \\
Adaba & 18.1 & 3.25 & 5.07 & 12.7 & 60.9 \\
Dodola & 17.5 & 3.29 & 5.45 & 13.3 & 60.5 \\
Dima & 17.2 & 3.34 & 6.37 & 9.37 & 63.7 \\
Mean & 19.9 & 3.34 & 11.7 & 60.3 \\
SD & 3.1 & 0.12 & 1.12 & 1.9 & 2.2 \\
\hline
\end{tabular}

TABLE 3: Relative percentage composition of fatty acids detected in leaves of Urtica simensis collected from six different districts in Ethiopia.

\begin{tabular}{|c|c|c|c|c|c|c|c|c|c|}
\hline Peak no. & Name, symbol & Dilla & Bule & Hula & Adaba & Dodola & Dima & Mean & SD \\
\hline 1 & Lauric acid, C12:0 & 0.19 & 0.17 & 0.10 & 0.17 & 0.13 & 0.09 & 0.14 & 0.04 \\
\hline 2 & Myristic acid, C14:0 & ND & 0.07 & 0.04 & 0.10 & 0.13 & 0.04 & 0.08 & 0.04 \\
\hline 3 & Hypogeic acid, C16:1 $(n-9)$ & ND & 0.49 & 0.06 & 0.38 & 0.42 & 0.06 & 0.28 & 0.21 \\
\hline 4 & Palmitoleic acid, C16:1 $(n-7)$ & 1.66 & 2.20 & 1.89 & 2.27 & 2.04 & 2.25 & 2.05 & 0.24 \\
\hline 5 & Palmitic acid, C16:0 & 18.6 & 19.9 & 16.6 & 20.8 & 18.0 & 16.2 & 18.4 & 1.80 \\
\hline 6 & Margaric acid, C17:0 & 0.16 & 0.18 & 0.13 & 0.18 & 0.15 & 0.12 & 0.15 & 0.03 \\
\hline 7 & Linoleic acid, C18:2(n-6) & 12.6 & 15.3 & 17.9 & 17.5 & 15.5 & 23.9 & 17.1 & 3.80 \\
\hline 8 & $\alpha$-Linolenic acid, C18:3 $(n-3)$ & 38.9 & 40.6 & 47.4 & 34.0 & 34.4 & 45.4 & 40.1 & 5.50 \\
\hline 9 & Oleic acid, C18:1 $(n-9)$ & 0.54 & 0.61 & 0.40 & 0.52 & 0.63 & 0.42 & 0.52 & 0.10 \\
\hline 10 & Stearic acid, C18:0 & 2.97 & 3.12 & 2.28 & 3.71 & 3.15 & 2.22 & 2.91 & 0.57 \\
\hline 11 & Dihomo- $\gamma$-linolenic acid, C20:3 $(n-6)$ & ND & 0.14 & 0.38 & ND & ND & ND & 0.26 & 0.17 \\
\hline 12 & Arachidonic acid, C20:4 $(n-6)$ & ND & 0.38 & 0.23 & ND & ND & ND & 0.31 & 0.10 \\
\hline 13 & Arachidic acid, C20:0 & 11.8 & 8.72 & 6.21 & 8.33 & 12.6 & 4.29 & 8.67 & 3.19 \\
\hline 14 & Heneicosylic acid, C21:0 & 0.82 & 0.60 & 0.38 & 0.86 & 0.65 & 0.32 & 0.60 & 0.22 \\
\hline 15 & Behenic acid, C22:0 & 7.10 & 4.64 & 3.71 & 6.91 & 6.58 & 2.29 & 5.20 & 1.97 \\
\hline 16 & Lignoceric acid, C24:0 & 4.68 & 2.90 & 2.30 & 4.24 & 5.48 & 2.29 & 3.65 & 1.34 \\
\hline
\end{tabular}

ND is not detected.

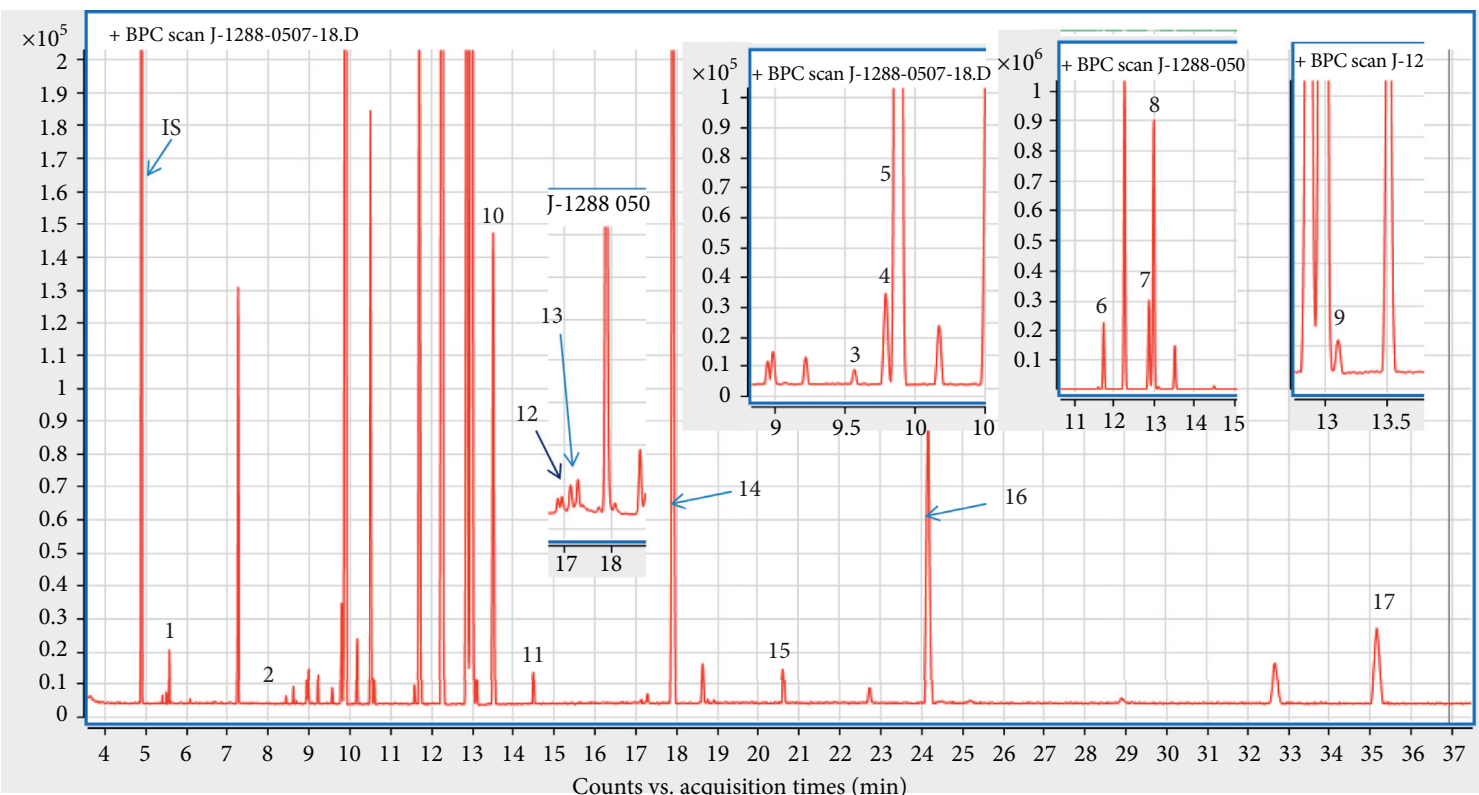

FIgURE 1: GC-MS chromatogram of methyl esters of fatty acids present in leaves of Urtica simensis collected from Hula district. IS is an internal standard (undecanoic acid).

acid content of the leaves of Urtica simensis. The result is, generally, similar to other studies on wild vegetables [23-25] that have reported the same three main fatty acids
( $\alpha$-linolenic, palmitic, and linoleic acids), with $\alpha$-linolenic acid being the most abundant fatty acid with compositions in the range $30-60 \%$. 
TABLE 4: The concentrations ( $\mathrm{mg} \mathrm{kg}^{-1}$ dry weight) of the fatty acids determined in the leaves of Urtica simensis grown in different locations in Ethiopia.

\begin{tabular}{|c|c|c|c|c|c|c|c|}
\hline Fatty acid & Dilla Zuria & Bule & Hula & Adaba & Dodola & Dima & Mean \\
\hline Palmitoleic acid & 68.08 & 178.0 & 191.1 & 140.8 & 69.38 & 179.9 & 137.9 \\
\hline Palmitic acid & 760.2 & 1614 & 1676 & 1294 & 615.0 & 1296 & 1209 \\
\hline Linoleic acid & 516.4 & 1237 & 1812 & 1087 & 529.2 & 1907 & 1181 \\
\hline$\alpha$-Linolenic acid & 1590 & 3286 & 4796 & 2116 & 1173 & 3621 & 2764 \\
\hline Oleic acid & 22.09 & 49.82 & 40.61 & 32.56 & 21.49 & 33.58 & 33.36 \\
\hline Stearic acid & 121.7 & 252.8 & 230.6 & 230.6 & 107.4 & 177.3 & 186.8 \\
\hline Arachidic acid & 483.7 & 706.5 & 628.3 & 518.1 & 429.6 & 342.4 & 518.1 \\
\hline Heneicosylic acid & 33.71 & 48.49 & 38.32 & 53.18 & 22.25 & 25.65 & 36.93 \\
\hline Behenic acid & 290.6 & 375.0 & 375.6 & 429.3 & 224.1 & 182.9 & 312.9 \\
\hline Lignoceric acid & 191.4 & 235.2 & 232.4 & 263.4 & 186.5 & 182.6 & 215.3 \\
\hline
\end{tabular}

Besides the three main fatty acids, the leaves also contained a considerable amount of arachidic acid (average $7.9 \%$ ). Leaves of Urtica simensis contained a significantly lower amount of oleic acid (0.5\%) when compared with some other common leafy vegetables reported in the literature, for example, Chinese cabbage (Brassica chinensis) $(9.8 \%)$ and spinach (Spinacia oleracea) $(6.2 \%)$, while it is slightly lower than watercress (Nasturtium officinale) $(1.0 \%)$, mint (Mentha viridis) (1.0\%), and parsley (Petroselinum crispum) (0.8\%) [26].

The nutritional quality of the leaves of Urtica simensis with respect to their fatty acid composition was evaluated. Unsaturated fatty acids constituted the largest proportion (average $62.4 \%$ ) of the total fatty acid. This is, for example, comparable with the total unsaturated fatty acid content of Amaranthus hybridus (64.8\%) and Corchorus olitorius $(68.8 \%)$ [27]. The unsaturated fatty acids were mainly of polyunsaturated fatty acids (average 59.8\%) composed of $\alpha$-linolenic and linoleic acids, with only a small amount of monounsaturated fatty acids (average 2.6\%) composed of palmitoleic and oleic acids.

The ratio of total unsaturated to total saturated fatty acids was 1.62. This ratio determines the nutritional quality of dietary fats; the higher the ratio, the better the nutritional quality. This is because a higher proportion of unsaturated fatty acids in the diet is associated with a reduced risk of heart diseases [28].

The leaves of Urtica simensis were found to be rich in $\alpha$-linolenic and linoleic acids. These two constituted about $59.8 \%$ of the total fatty acids. These are essential fatty acids that cannot be synthesized in the human body and have to be supplied from foods. They play a preventive role in cardiovascular diseases and a reduction of both total and highdensity lipoprotein cholesterols. The higher proportion of these fatty acids in the leaves of Urtica simensis makes them beneficial to the consumer. The essential fatty acid composition of leaves of Urtica simensis is comparable with that of several common leafy vegetable foods like Chinese cabbage $(59.3 \%)$, watercress $(57.0 \%)$, spinach $(56.7 \%)$, and parsley $(56.7 \%)$ [26].

Increased intake of long-chain $n-3$ polyunsaturated fatty acids, especially eicosapentaenoic acid $(20: 5 n-3)$ and docosahexaenoic acid $(22: 6 n-3)$, has been indicated to reduce the risk of coronary heart disease, improve inflammatory conditions, reduce plasma triacylglycerol levels, and lower blood pressure $[29,30]$. The precursor of these fatty acids is $\alpha$-linolenic acid $(18: 3 n-3)$, where, in the human body, it is converted to $20: 5 n-3$ and $22: 6 n-3$ fatty acids. In light of this, the presence of a high proportion of $\alpha$-linolenic acid (41.9\%) in its fatty acid fraction makes the leaves of Urtica simensis beneficial for human consumption.

Various investigators have pointed out the necessity of having an appropriate balance of the essential fatty acids (linoleic acid and $\alpha$-linolenic acids) in the diet for improved human health [27]. Contrary to these, FAO [31] has stated that there is no rationale for a specific recommendation for linoleic acid to $\alpha$-linolenic ratio in the diet. The linoleic to $\alpha$-linolenic acid ratio of leaves of Urtica simensis is higher than that found in Chinese cabbage $(0.16 \%)$, watercress $(0.19 \%)$, spinach $(0.25 \%)$, and mint $(0.16 \%)$ while it is lower than that of parsley $(0.78 \%)$ [26].

3.3. Total Polyphenol Content and Antioxidant Activity. The leaf samples of Urtica simensis were found to contain an average of $3.04 \mathrm{mgGAE} \mathrm{g}^{-1}$ of total polyphenol, $2.37 \mathrm{mgCE}$ $\mathrm{g}^{-1}$ of total flavonoid, and $2.02 \mathrm{mgAAE} \mathrm{g}^{-1}$ of antioxidant activity (Table 5). These results indicate that flavonoids are the major constituents that make the polyphenol fraction of the leaves.

There was a high variation in the polyphenol content among samples collected from different locations. Total polyphenol varied in the range $2.18-4.84 \mathrm{mgGAE}^{-1}$ and total flavonoid in the range 1.35-4.46 $\mathrm{mgCE} \mathrm{g}^{-1}$ across the six samples. This is obvious as these are secondary metabolites and their levels in plants depend highly on environmental factors, such as climate, altitude, and soil type.

The result of the present study was compared with that reported for other leafy vegetables [32-34]. The total polyphenol content of Urtica simensis leaves (3.04 mgGAE $\mathrm{g}^{-1}$ ) appears to be moderate compared to the other leafy vegetables. It is about three times higher than some of the species, such as Asteracantha longifolia and Alternanthera sessilis, while it is lower by the same magnitude than some other species, such as Gymnema lactiferum and Sesbania grandiflora.

Regarding flavonoids, the total concentration determined in Urtica simensis leaves $\left(2.37 \mathrm{mgCE}^{-1}\right)$ falls within 
TABLE 5: The total concentration of polyphenols (mgGAE $\mathrm{g}^{-1}$ dry sample), flavonoids ( $\mathrm{mgCE}^{-1}$ dry sample), and antioxidant activity (mgAAE ${ }^{-1}$ dry sample) determined in the leaves of Urtica simensis collected from six different locations of Ethiopia.

\begin{tabular}{lccc}
\hline $\begin{array}{l}\text { Sampling } \\
\text { districts }\end{array}$ & $\begin{array}{c}\text { Total } \\
\text { polyphenol }\end{array}$ & $\begin{array}{c}\text { Total } \\
\text { flavonoid }\end{array}$ & $\begin{array}{c}\text { Antioxidant } \\
\text { activity }\end{array}$ \\
\hline Dilla Zuria & 2.67 & 2.18 & 1.65 \\
Bule & 3.15 & 1.35 & 2.20 \\
Hula & 2.18 & 1.51 & 1.58 \\
Adaba & 2.92 & 2.41 & 1.68 \\
Dodola & 2.48 & 2.28 & 1.66 \\
Dima & 4.84 & 4.46 & 3.36 \\
Mean & 3.04 & 2.37 & 2.02 \\
SD & 0.94 & 1.11 & 0.69 \\
\hline
\end{tabular}

the range reported for thirteen species of Amaranthus (1.50-4.10 $\left.\mathrm{mgCE} \mathrm{g}^{-1}\right)$ by Jiménez-Aguilar and Grusak [32].

\section{Conclusion}

This study has revealed that leaves of Urtica simensis contain a significant amount of dietary and health important biochemicals. In particular, the leaves are found to be rich in carbohydrates and minerals (ash). The leaves have a moderate fat content that is rich in the essential fatty acids. This wild vegetable can be considered as an easily accessible and valuable food.

\section{Abbreviations}

DPPH: 2,2-Diphenyl-1-picrylhydrazyl

TPC: Total phenolic contents

TFC: Total flavonoid content

GAE: Gallic acid equivalent

CE: Catechin equivalent

AAE: Ascorbic acid equivalent

TUSFA: Total unsaturated fatty acids

TSFA: Total saturated fatty acids.

\section{Data Availability}

The datasets used and/or analyzed during the current study are available from the corresponding author on reasonable request.

\section{Conflicts of Interest}

The authors (Koju B. Bayba, Amare A. Dubale, Bewketu Mehari, and Minaleshewa Atlabachew) declare that there are no conflicts of interest.

\section{Authors' Contributions}

KBB conducted the lab work; AAD, BM, and MA designed the study; KBB and MA collected the data and drafted the manuscript; and $\mathrm{AAD}$ and $\mathrm{BM}$ edited the manuscript. All authors read and approved the final manuscript.

\section{Acknowledgments}

The authors would like to acknowledge Dilla University and Bahir Dar University of Ethiopia for providing laboratory facilities. Mr. Koju Bedekach is thankful to the SNNPRS Bureau of Education for sponsoring his study.

\section{References}

[1] T. Seifu, B. Mehari, M. Atlabachew, and B. Chandravanshi, "Polyphenolic content and antioxidant activity of leaves of Urtica simensis grown in Ethiopia," Latin American Applied Research, vol. 47, pp. 35-40, 2017.

[2] J. Zhang, Y. Ding, H. Dong, H. Hou, and X. Zhang, "Distribution of phenolic acids and antioxidant activities of different bran fractions from three pigmented wheat varieties," Journal of Chemistry, vol. 2018, Article ID 6459243, 9 pages, 2018.

[3] Y. Xu, S. Burton, C. Kim, and E. Sismour, "Phenolic compounds, antioxidant, and antibacterial properties of pomace extracts from four Virginia-grown grape varieties," Food Science \& Nutrition, vol. 4, no. 1, pp. 125-133, 2016.

[4] K. A. Sir Elkhatim, R. A. A. Elagib, and A. B. Hassan, "Content of phenolic compounds and vitamin $\mathrm{C}$ and antioxidant activity in wasted parts of Sudanese citrus fruits," Food Science \& Nutrition, vol. 6, no. 5, pp. 1214-1219, 2018.

[5] D. Alemayehu, G. Desse, K. Abegaz, B. B. Desalegn, and D. Getahun, "Proximate, mineral composition and sensory acceptability of homemade noodles from stinging nettle (Urtica simensis) leaves and wheat flour blends," International Journal of Food Science and Nutrition Engineering, vol. 6, no. 3, pp. 55-61, 2016.

[6] W. Tsegaye, K. Urga, and K. Asres, "Antidiabetic activity of samma (Urtica simensis hochst. Ex. A. Rich.) in streptozotocin-induced diabetic mice," Ethiopian Pharmaceutical Journal, vol. 27, no. 2, pp. 75-82, 2010.

[7] A. Enyew, Z. Asfaw, E. Kelbessa, and R. Nagappan, "Ethnobotanical study of traditional medicinal plants in and around fiche district, Central Ethiopia," Current Research Journal of Biological Sciences, vol. 6, no. 4, pp. 154-167, 2014.

[8] G. Alemayehu, Z. Asfaw, and E. Kelbessa, "Ethnobotanical study of medicinal plants used by local communities of Minjar-Shenkora district, north shewa zone of amhara region, Ethiopia," Journal of Medicinal Plants Studies, vol. 3, no. 6, pp. 1-11, 2015.

[9] E. Lulekal, Z. Asfaw, E. Kelbessa, and P. van Damme, "Wild edible plants in Ethiopia: a review on their potential to combat food insecurity," Afrika Focus, vol. 24, no. 2, pp. 71-121, 2011.

[10] G. J. Huffman and D. T. Bolvin, TRMM and other Data Precipitation Data Set Documentation, Vol. 28, NASA, Greenbelt, USA, 2013.

[11] AOAC, Official Methods of Analysis of AOAC International, Vol. 1, Association of Analytical communities, Arlington, VA, USA, 15th edition, 1990.

[12] F. N. Nweke, B. E. Ubi, and K. J. Kunert, "Determination of proximate composition and amino acid profile of Nigerian sesame (Sesamum indicum L.) cultivars," Nigerian Journal of Biotechnology, vol. 23, pp. 5-12, 2011.

[13] B. Mehari, M. Redi-Abshiro, B. S. Chandravanshi, S. Combrinck, R. McCrindle, and M. Atlabachew, "GC-MS profiling of fatty acids in green coffee (Coffea arabica L.) beans and chemometric modeling for tracing geographical origins from Ethiopia," Journal of the Science of Food and Agriculture, vol. 99, no. 8, pp. 3811-3823, 2019. 
[14] Y. Liu, X. Luo, Z. Lan, J. Tang, P. Zhao, and H. Kan, "Ultrasonic-assisted extraction and antioxidant capacities of flavonoids from Camellia fascicularis leaves," CyTA-Journal of Food, vol. 16, no. 1, pp. 105-112, 2018.

[15] D. Marinova, F. Ribarova, and M. Atanassova, "Total phenolics and total flavonoids in Bulgarian fruits and vegetables," Journal of the University of Chemical Technology and Metallurgy, vol. 40, pp. 255-260, 2005.

[16] A. N. Alamgir, A. Rahman, and M. Rahman, "Secondary metabolites and antioxidant activity of the crude leaf extract of Bacopa monniera L., pennel and Coccinia grandis L," Journal of Pharmacognosy and Phytochemistry, vol. 3, pp. 226-230, 2014.

[17] U. B. Shemishere, J. E. Taiwo, N. Erhunse, and E. S. Omoregie, "Comparative study on the proximate analysis and nutritional composition of Musanga cercropioides and Maesobotyra barteri leaves," Journal of Applied Sciences and Environmental Management, vol. 22, no. 2, pp. 287-291, 2018.

[18] O. A. Akinwunmi and F. O. Omotayo, "Proximate analysis and nutritive values of ten common vegetables in south-west (Yoruba land) Nigeria," Communications in Applied Sciences, vol. 4, pp. 79-91, 2016.

[19] K. M. E. Iheanacho and A. C. Udebuani, "Nutritional composition of some leafy vegetables consumed in Imo state, Nigeria," Journal of Applied Science and Environmental Management, vol. 13, no. 3, pp. 35-38, 2009.

[20] R. Vidrih, S. Filip, and J. Hribar, "Content of higher fatty acids in green vegetables," Czech Journal of Food Sciences, vol. 27, no. 1, pp. S125-S129, 2009.

[21] D. Villarreal, A. Laffargue, H. Posada, B. Bertrand, P. Lashermes, and S. Dussert, "Genotypic and environmental effects on coffee (Coffea arabica L.) bean fatty acid profile: impact on variety and origin chemometric determination," Journal of Agricultural and Food Chemistry, vol. 57, no. 23, pp. 11321-11327, 2009.

[22] S. Boulom, J. Robertson, N. Hamid, Q. Ma, and J. Lu, "Seasonal changes in lipid, fatty acid, $\alpha$-tocopherol and phytosterol contents of seaweed, Undaria pinnatifida, in the Marlborough Sounds, New Zealand," Food Chemistry, vol. 161, pp. 261-269, 2014.

[23] L. Barros, A. M. Carvalho, and I. C. F. R. Ferreira, "The nutritional composition of fennel (Foeniculum vulgare): shoots, leaves, stems and inflorescences," LWT-Food Science and Technology, vol. 43, no. 5, pp. 814-818, 2010.

[24] C. I. Vardavas, D. Majchrzak, K. H. Wagner, I. Elmadfa, and A. Kafatos, "Lipid concentrations of wild edible greens in Crete," Food Chemistry, vol. 99, no. 4, pp. 822-834, 2006.

[25] R. Alarcón, L. T. Ortiz, and P. García, "Nutrient and fatty acid composition of wild edible bladder campion populations [Silene vulgaris (Moench.) Garcke]," International Journal of Food Science and Technology, vol. 41, no. 10, pp. 1239-1242, 2006.

[26] C. Pereira, D. Li, and A. J. Sinclair, "The alpha-linolenic acid content of green vegetables commonly available in Australia," International Journal for Vitamin and Nutrition Research, vol. 71, no. 4, pp. 223-228, 2001.

[27] A. Adeyeye, O. D. Ayodele, G. A. Akinnuoye, and W. Sulaiman, "Proximate composition and fatty acid profiles of two edible leafy vegetables in Nigeria," American Journal of Food, Nutrition and Health, vol. 3, pp. 51-55, 2018.

[28] K. Ajewole and A. Adeyeye, "Seed oil of white star apple (Chrysophyllum albidum)-physicochemical characteristics and fatty acid composition," Journal of the Science of Food and Agriculture, vol. 54, no. 2, pp. 313-315, 1991.
[29] W. S. Harris, “ $n-3$ fatty acids and lipoproteins: comparison of results from human and animal studies," Lipids, vol. 31, no. 3, pp. 243-252, 1996.

[30] M. J. James, R. A. Gibson, and L. G. Cleland, "Dietary polyunsaturated fatty acids and inflammatory mediator production," The American Journal of Clinical Nutrition, vol. 71, no. 1, pp. 343s-348s, 2000.

[31] FAO, Fats and Fatty Acids in Human Nutrition (Report of an Expert Consultation), FAO Food and Nutrition Paper 91, Geneva, Switzerland, 2008, http://www.fao.org/3/a-i1953e. pdf.

[32] D. M. Jiménez-Aguilar and M. A. Grusak, "Minerals, vitamin C, phenolics, flavonoids and antioxidant activity of Amaranthus leafy vegetables," Journal of Food Composition and Analysis, vol. 58, pp. 33-39, 2017.

[33] K. D. P. P. Gunathilake and K. K. D. S. Ranaweera, "Antioxidative properties of 34 green leafy vegetables," Journal of Functional Foods, vol. 26, pp. 176-186, 2016.

[34] M. Moyo, S. O. Amoo, B. Ncube, A. R. Ndhlala, J. F. Finnie, and J. Van Staden, "Phytochemical and antioxidant properties of unconventional leafy vegetables consumed in southern Africa," South African Journal of Botany, vol. 84, pp. 65-71, 2013. 